\title{
NUMERICAL EVALUATION OF THE SOLAR COLLECTORS SELF- SHADING RELATED TO THEIR BUILDING INTEGRATION
}

\author{
Andrei DAMIAN -Associate Professor, PhD, Technical University of Civil Engineering, Faculty of Building \\ Services and Equipment, e-mail: andrei.damian@utcb.ro \\ Marian ALEXANDRU - MSc Engineer, PhD student, Technical University of Civil Engineering, Faculty of \\ Building Services and Equipment, e-mail: alexandru.marian@phd.utcb.ro \\ Tiberiu CATALINA - Associate Professor, PhD, Technical University of Civil Engineering, Faculty of Building \\ Services and Equipment, e-mail: tiberiu.catalina@utcb.ro
}

\begin{abstract}
In view of the recent preoccupation at worldwide level, for the integration of the solar systems components within the building skin, we made a numerical investigation in order to assess the opportunity to implement a long string of solar panels along a horizontal or vertical building surface.The study analyses deals with the phenomenon of self-shading, which appears in the case of medium and large solar systems that use solar panels placed one behind the other, along the same row (individual string), but also under the shape of parallel rows (parallel strings). The study creates a mathematical instrument for the evaluation of the shaded surface depending on the location of the panels and the relative position of the Sun. The shading-caused energy loss is analysed along the one-year period, for each of the 12 months, while the panels are considered either placed on a horizontal surface such as a building terrace, or on a vertical surface, such as a building facade. The simulations are made for six Romanian cities located in different climatic zones, characterized by different levels of solar radiation.
\end{abstract}

Keywords: façades, sun position, azimuth angle, solar radiation

\section{Introduction}

The present paper has, as main objective, the study of the opportunity to implement solar collectors on the building vertical surfaces that could be the building façades. In the last decade, at the EU level, the integration of the solar components within the buildings has become a major target of architects, engineers and building owners, in order to respect the recommendations of the EU Strategic Energy Technology (SET) Plan (from now to 2030), to increase gradually the solar fraction of the building technologies.

Knowing that the position of the solar thermal or PV collectors on the building facades should respect architectural and aesthetical criteria, the authors intended to outline the influence of the collector's self-shading phenomenon that could reduce the solar useful energy capture of the collectors. Therefore, a geometrical study of the self-shading areas produced by the nearby collectors installed on a building façade was performed, directly related to the cardinal orientation of that façade. The study goes furthermore, by analysing the self-shading of the same collector types placed on the building terrace (i.e. horizontal surface), a common location selected for the solar panels in many buildings.

In order to fulfil the paper objective, the study is based on a geometrical analysis performed on the vertically superposed solar collectors placed on a building wall, as well as on the neighbouring horizontal collectors located on a building terrace, to assess the self-shading surface which would reduce the beam solar radiation incident on the collectors, lowering the efficiency of the solar energy capture. These situations could frequently occur in the engineering practice of the Solar Systems integrated in the buildings, so our analysis could be a useful point 
of view for the occultation of self-shading phenomena that would lower the useful solar energy converted by the collectors.

\section{Evaluation of the self-shading phenomena for individual strings of solar panels}

\subsection{State of the art of the Solar Systems integration within buildings}

The integration of the solar thermal systems components within the buildings became a major interest topic in the latest ten years, due to the growing preoccupations to increase the renewable energies role on the building sector. Many european regulations and actions have been developped consequently, one of the more important being:

- The 31/2010/EU Directive (EPBD Recast), on the Buildings Energy Performance [1];

- The EU Strategic Energy Technology (SET) Plan [2], aiming to accelerate the development and deployment of low-carbon technologies; this Plan seeks to improve new technologies and bring down costs by coordinating national research efforts and helping to finance projects;

- The "Solar Heating and Cooling Technology Roadmap" [3] from the EU's RHC Platform, as well as the "Deutsche Solarthermie-Strategie Plattform (DSTTP)" [4]

These regulations had more general behaviour, establishing a framework for more concrete actions to be done, in order to fulfill their objectives. On this road, we mention two important publications:

- The "Research and Development Roadmap for facade-integrated solar thermal systems" report released by the Fraunhofer Institute for Solar Energy Systems [5] and,

- "Building Integration of Solar Thermal Systems. Design and Applications Handbook" [6], released from the European research project COST Action TU1205.

Both documents intend to outline some "best practices" related to the technology of integration for Solar Thermal Systems within buildings, by presenting several case studies settled up in the European countries participating at these actions. Similar preoccupations have been developed in the sector of PV systems integrations within buildings.

Lamnatou et al. performed a comprehensive critical review on Solar Thermal systems (STS), solar systems that produce electricity (PV) or combined solar systems (PV-T). Building Integrated Solar Thermal (BIST) are emphasized and, where possible, compared to Building Added Systems (BAS), showing that BIST systems require more experimental and numerical investigations, especially in the case of active solar systems. [7,8]. V. Delisle et al., which makes a Cost-Benefit analysis of the integration of PV-T elements in building facades, defines Building Integrated Photovoltaic (BIPV) as multifunctional solar energy collectors that are components of the building envelope. Besides generating electricity, they protect the building against environmental stress, acting as a building material [9]. The same definition is used by Shukla et al., who makes a recent review of several contributions to BIPV technologies [10]. Similarly, C. Maurer et al. defines BIST as solar modules integrated into the building architecture showing that, apart from their primary function, also produce other effects such as sound insulation or protection against wind and direct solar radiation [11].

On the other hand, in the case of modern commercial buildings, where the energy demand is high, there is a lack of space available on the building's terrace due to the numerous equipment and installations necessary for its operation. Obviously, this type of building requires the implementation of large systems of solar collectors, hence the need to place them, also, on the vertical surfaces that provide optimal orientation [12]. The implementation of solar collectors on 
vertical surfaces less exposed to the sun than terraces in order to increase the solar caption surface can prove to be an energy-efficient solution [13]. Yan Li et al. developed a new methodology for assessing the economic performance of solar systems combining the Life Cycle Cost (LCC) approach with a graphical method. Using this methodology, a case study is carried out on a building with multiple facades of different orientations and angles of inclination with respect to the horizontal plane. Thus, it is shown that changing the slope of solar collectors located on the facades can significantly reduce the investment payback time [14].

Although the collectors located on the facades are often perceived as elements with a negative impact on the building's architecture, the solution presents some advantages over their location on the terraces or sloped roofs. Thus, due to the possibility of variation of the tilt angles for the panels located in less visible places such as terraces, their energy harvesting potential can be maximized. As a result, it appears the risk of heat overproduction in the summertime that leads to the increase of the electrical energy consumption during their operation, as well as the difficulty to design a system according to the energy demand. In middle-latitudes geographic areas, the location of the collectors on vertical surfaces eliminates the risk of overproduction due to the occurrence of self-shading phenomenon, which leads to a more linear distribution of the solar fraction over one-year period [15].

Other authors focused their studies on the electrical and thermal performances of the PV-T systems integrated in buildings [16-19].

\subsection{Geometrical theory of the solar radiation captured by building surfaces}

In the applications of the solar energy, the knowledge of the geometrical parameters of the solar trajectory is needed. The most important angles having a role in the estimation of the solar irradiance in a point $P$ from the Earth surface are outlined in the figure 1:

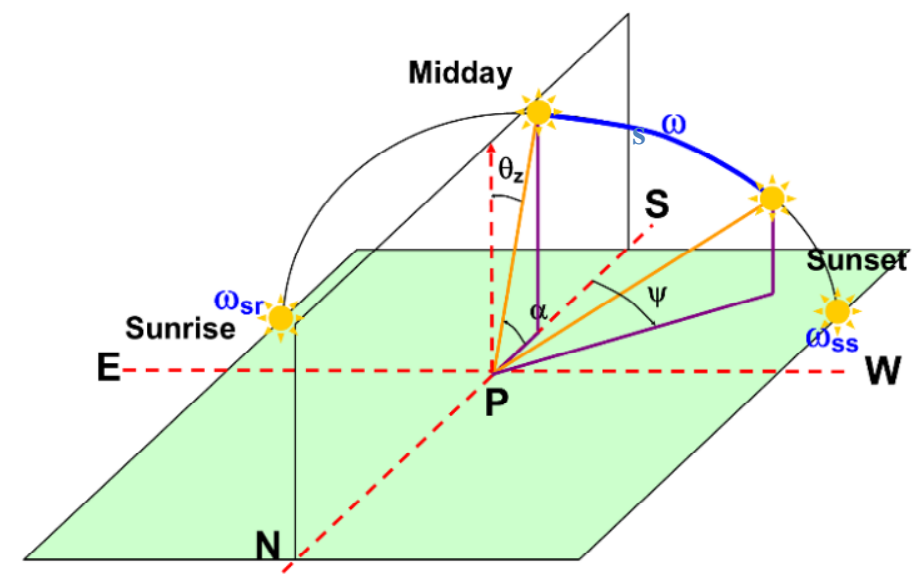

Fig. 1 - The angles for the evaluation of the solar irradiance in a point $\mathrm{P}$ on the earth [6]

The angles represented in figure 1 are the following ones:

- The hourly angle $\omega \mathrm{s}$ is also known as solar time (ST) angle expressed by (degrees):

$$
\omega_{s}=15(12-S T)
$$

while $\omega s r$ and $\omega$ ss represent the angles corresponding to the sunrise and sunset, respectively;

- The solar height angle $\alpha$ (or solar elevation, in degrees) is the angle between the horizontal plane and the the line joining the centers of the Earth and the Sun; it is expressed by:

$$
\alpha=\arcsin \left[\sin (\varphi) \sin (\delta)+\cos (\varphi) \cos (\delta) \cos \left(\omega_{\mathrm{s}}\right)\right]
$$


where:

- the declination angle $\delta$ (degrees) is the angle between the equatorial plane and the straight line joining the centers of the Earth and the Sun, being determined by mathematical laws governing the annual solar trajectory related to the Earth position, and

- the solar latitude angle $\varphi$ (degrees) corresponds to the geographical latitude angle from the Earth hemisphere (Southern or Northern)

- The solar azimuth $\Psi$ angle (degrees) is the angle between the projection of the straight line joining the centers of the Earth and the Sun on the horizontal plane and the axis South-North; this angle could be positive or negative depending on the variable sun position over the daytime; the solar azimuth could be written as:

$$
\Psi=\operatorname{arcos}\left[\frac{\sin (\alpha) \sin (\varphi)-\sin (\delta)}{\cos (\alpha) \cos (\varphi)}\right]
$$

- The zenith angle $\theta z$ (degrees) is the complementary angle of the solar altitude angle $\alpha$ for a given geographical position, otherwise saying:

$$
\theta_{z}=\frac{\pi}{2}-\alpha
$$

In the analysis of the Solar Systems integrated in the building, it is very important to evaluate the incident radiation on a surface plane tilted with the angle $\beta$ from the horizontal plane.

This surface could be a collector surface placed along a wall or directly on the building roof or terrace (figure 2). For that, the incidence angle $\theta$ (deg) between the direct sun ray and the normal to the tilted plan could be calculated by the following equation:

$$
\begin{aligned}
& \theta=\operatorname{arcos}[(\sin (\varphi) \cos (\beta)-\cos (\varphi) \sin (\beta) \cos (\gamma)) \sin (\delta)+(\cos (\varphi) \cos (\beta)+ \\
& \sin (\varphi) \sin (\beta) \cos (\gamma)) \cos (\delta) \cos (\omega)+\cos (\delta) \sin (\beta) \sin (\gamma) \sin (\omega)
\end{aligned}
$$

where $\gamma$ (degrees) is the longitudinal angle measured from the local meridian.

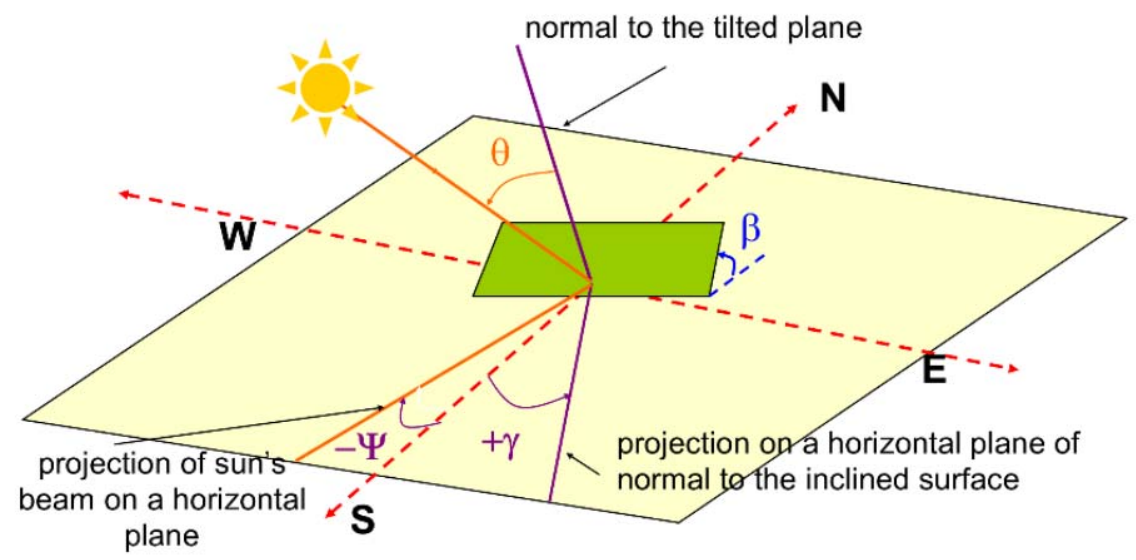

Fig. 2 - Position of the Sun related to a tilted plane [6]

\subsection{Case study: self-shading of vacuum collectors installed on vertical and horizontal surfaces}

In order to evaluate the performance of different solar collectors, we selected for our numerical study a vacuum-tube solar collector from the Viessmann manufacturer. This collector, having the code Vitosol 200T, has a very useful feature: its absorber plates could be rotated around their longitudinal axis. This feature allows increasing the solar yield of the collector, because the 
absorber plate could be optimally oriented towards the Sun when the collector's frame is mounted on a vertical surface, as a wall (figure 3).
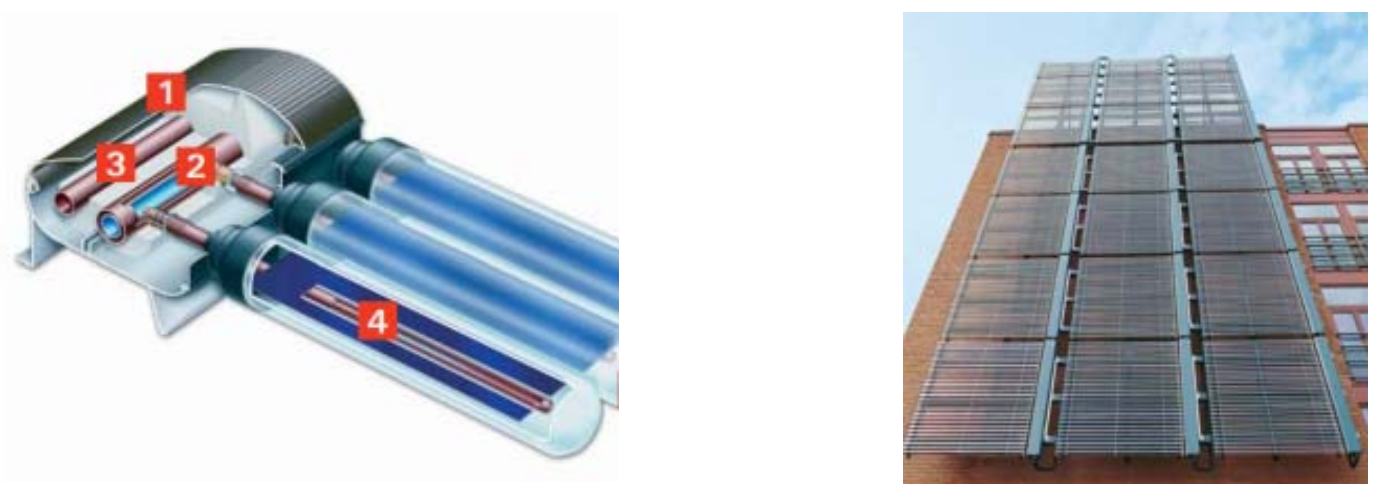

Fig. 3 - The vacuum-tube collector Vitosol 200T and its position on a vertical surface

The common practice in the field of solar collectors is to align them in series-parallel strings to cover a uniform surface, at the ground level (detached) or at the building level (tilted roof or terrace). Therefore, it is possible to encounter a negative phenomenon such as the self-shading of the panels, due to the fact that the panels are placed "one behind the other" on a string, relatively to the Sun incident rays.

The figure 4 presents the self-shading mode production for a string of rectangular tilted solar panels placed on a horizontal plane. The figure $4 \mathrm{a}$ outlines the behavior of the solar panels string for big solar height angles (bigger than the critical sun elevation $\alpha_{0}$ for which the distance between two neighboring panels was previously determined) and it could be noticed that all the panel's surfaces are exposed to the solar beam radiation and no shading occurs. The figure $4 \mathrm{~b}$ presents the winter case, when small solar height angles are characteristic, and the shadow area of the panels will depend on their tilt angle to horizontal plane, solar height angles and solar azimuth angle.
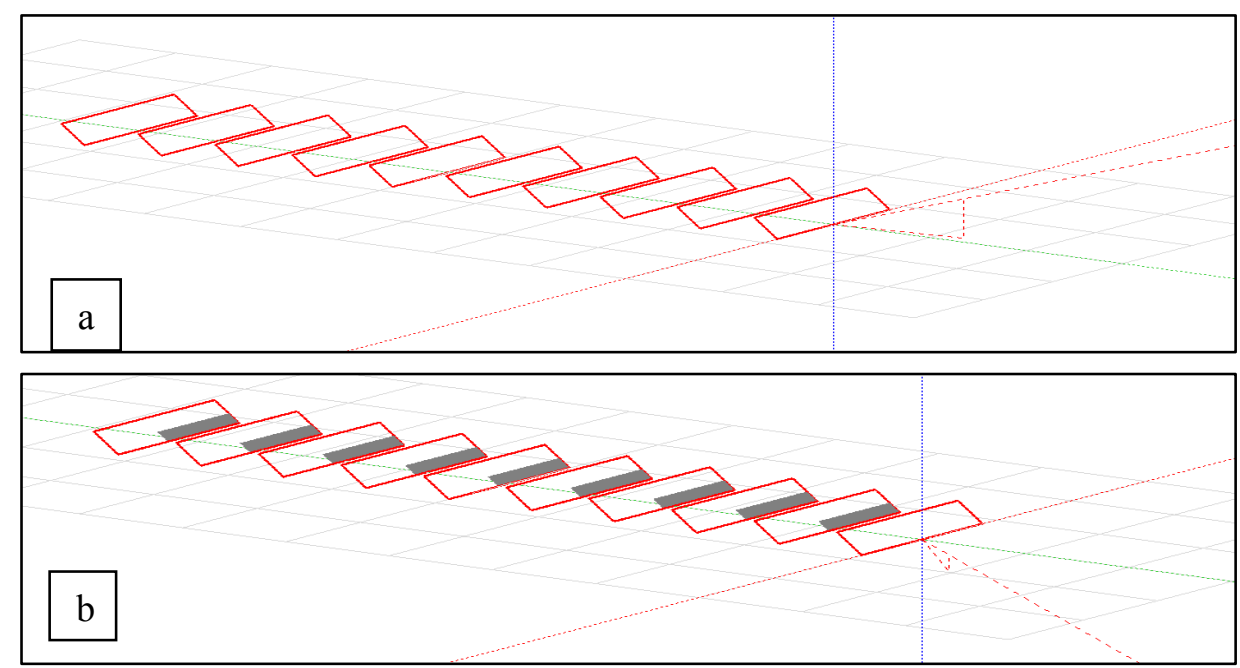

Fig.4 - Perspective view of the self-shading induced by the sun position relatively to a string of panels placed on a horizontal surface: a) no self-shading b) self-shading

The figure 5 presents the shading mode production for a string of rectangular tilted solar panels placed on a vertical plane. The physical phenomenon occurs in a totally opposite mode compared to the prior case. The self-shading appears especially during the summer period, at big solar 
height angles, bigger than the angle $\alpha_{0}$, as it could be seen in figure $5 \mathrm{a}$. For small solar height angles, the self-shading doesn't occur at all (figure 5b).

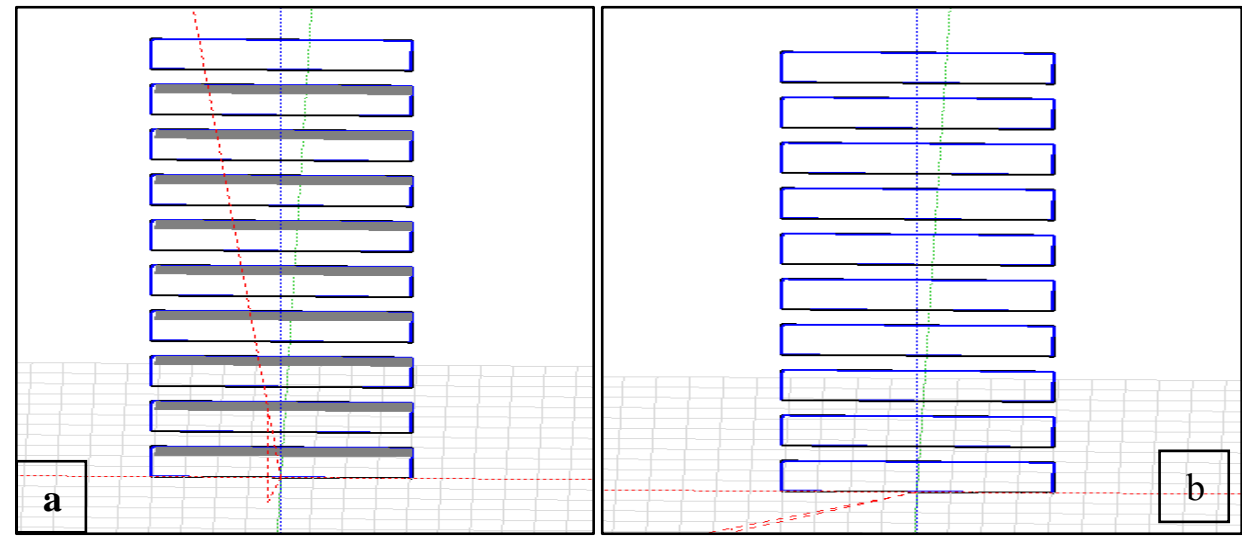

Fig.5 - Perspective view of the self-shading induced by the sun position relatively to a string of panels placed on a vertical surface: a) self-shading b) no self-shading

In the figure 6 is presented the geometrical calculation scheme for the determination of the optimal horizontal distance between two adjacent tilted panels placed on a horizontal surface. This distance $d$ (in $\mathrm{m}$ ) should be calculated in order to avoid the self-shading of the neighboring, adjacent panels. In order to make an optimization, the angle $\alpha_{0}$ from the figure 6 corresponds to the solar height angle from the winter solstice, measured at 12:00 AM in 21 December. For the remaining hours (before sunrise and sunset), the self-shading could appear depending on the solar height variation with respect to the angle $\alpha_{0}$. It could be easily seen from the figure 6 that, for solar height angles smaller than the angle $\alpha_{0}$, the self-shading will always occur, but this happens generally at daily hours when the solar beam radiation is quite weak (close to sunrise and sunset periods), so the direct effect of the shading is quite attenuated.

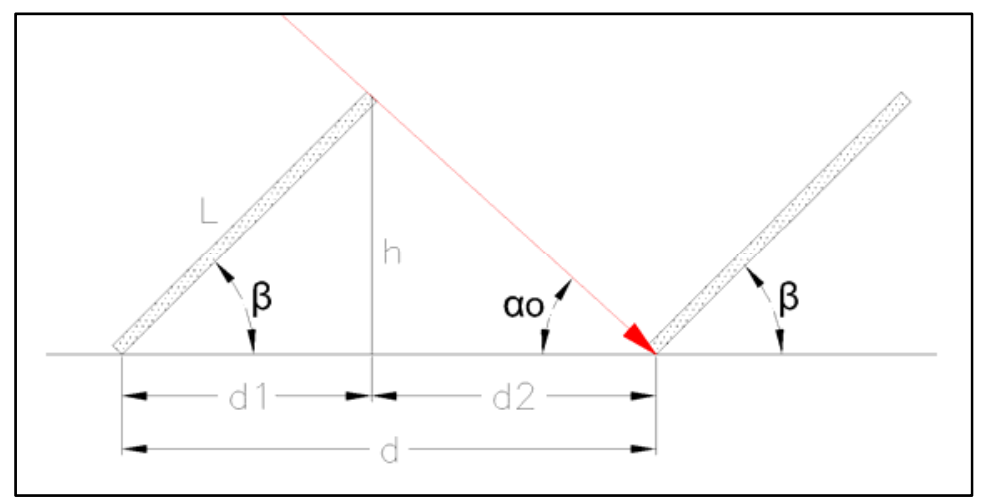

Fig.6 - Calculation of the distance between two adjacent panels placed on a horizontal surface

The calculation presumes that the length $L$ (in $\mathrm{m}$ ) of the solar panel is known, and also the tilt angle $\beta$ with respect to the horizontal plane and the optimal angle $\alpha_{0}$ previously determined. The normal $h$ to the horizontal plane that passes through the panel's peak forms, together with the solar ray and the panel's surface, two rectangular triangles, for whom will appear two projection lengths $d_{1}$ and $d_{2}$, (in $\mathrm{m}$ ) on the horizontal plane (figure 6). In such case, the optimal distance $\mathrm{d}$ between two adjacent panels will be the sum of $d_{1}$ and $d_{2}$, as follows:

$$
\begin{aligned}
& \cos \beta=\frac{d_{1}}{L} \quad \Rightarrow \quad d_{1}=L \cdot \cos \beta \\
& \sin \beta=\frac{h}{L} \quad \Rightarrow \quad h=L \cdot \sin \beta
\end{aligned}
$$




$$
\begin{aligned}
& \tan \alpha=\frac{h}{d_{2}} \Rightarrow d_{2}=h \cdot \tan \alpha=L \cdot \frac{\sin \beta}{\tan \alpha_{0}} \\
& d=d_{1}+d_{2}=L\left(\cos \beta+\frac{\sin \beta}{\tan \alpha_{0}}\right)
\end{aligned}
$$

In the figure 7 is presented the calculation scheme for the optimal distance between two adjacent panels placed on a vertical plane that could be a building wall. In this case, the solar caption surface will be represented by the absorbent flat plate of a vacuum-tube solar panel, knowing that this plate could be rotated to better catch the sun ray. The drawing reproduces a vertical cut through a system of two adjacent absorbent flat plates placed on a vertical wall, their longitudinal axis being parallel to the horizontal plane.

The possibility to rotate these plates around their longitudinal axis allows the variation of the tilt angle $\beta$ with respect to horizontal plane. In this case the distance $d$ between the centers of the adjacent plates is imposed by the panel's manufacturer, but some dependency relations could be written between this distance and the geometrical angles from figure 6 .

As we can see from the figure 7, a more important angle than $\beta$ appears to be its complementary angle, $\left(90^{\circ}-\beta\right)$, and also the angle formed between the sun ray and the vertical surface, $\left(90^{\circ}-\alpha_{0}\right)$ :

$$
\begin{aligned}
& \cos \left(\frac{\pi}{2}-\beta\right)=\frac{d_{1}}{L} \Rightarrow d_{1}=L \cdot \cos \left(\frac{\pi}{2}-\beta\right) \\
& \sin \left(\frac{\pi}{2}-\beta\right)=\frac{h}{L} \quad \Rightarrow \quad h=L \cdot \sin \left(\frac{\pi}{2}-\beta\right) \\
& \tan \left(\frac{\pi}{2}-\alpha 0\right)=\frac{h}{d_{2}} \Rightarrow d_{2}=h \cdot \tan \left(\frac{\pi}{2}-\alpha 0\right)=L \cdot \frac{\sin \left(\frac{\pi}{2}-\beta\right)}{\tan \left(\frac{\pi}{2}-\alpha \mathrm{o}\right)}
\end{aligned}
$$

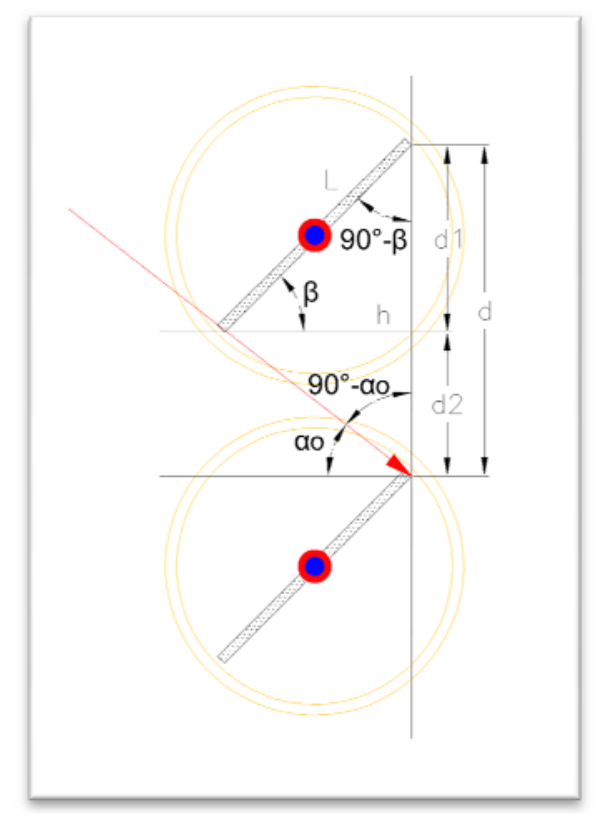

Fig.7 - Calculation of the distance between two adjacent panels placed on a vertical surface

By using the relations of symmetry for trigonometric functions, the expression of the distance $d$ from the equations set (7) could be written as:

$$
d=L\left(\sin \beta+\frac{\cos \beta}{\cot \alpha 0}\right)
$$

For solar height angles $\alpha$ smaller than the optimal angle $\alpha_{0}$, the self-shading phenomenon (total or partial) will occur, as it could be noticed from figure 8 , considering the darkened segment A'B' (noted " $u$ " as its length) from the "shaded" panel. In order to evaluate the solar energy loss resulting from this phenomenon, the shaded surfaces of the panels corresponding to this $u$-length segment should be determined for every hour. 


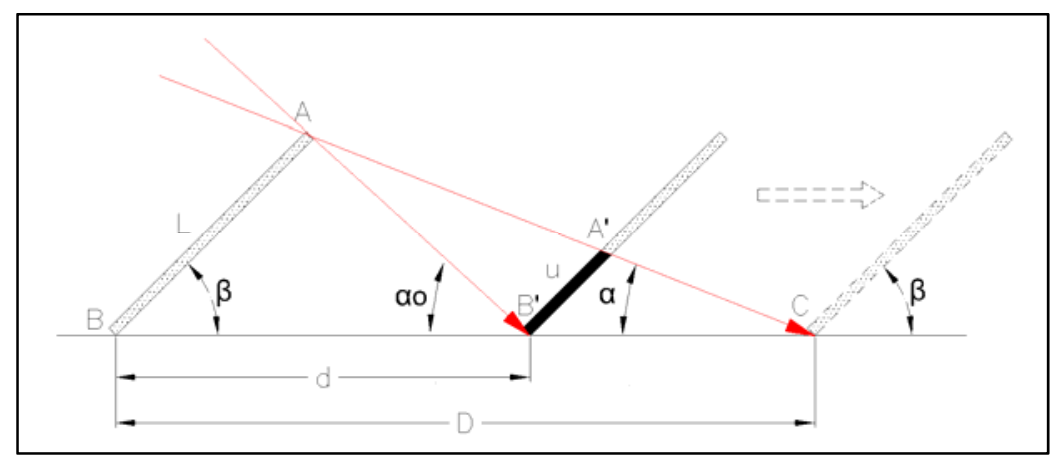

Fig.8 - Self-shading of the solar panels placed on a horizontal surface

If we consider a translation of the shaded surface previously determined until the point $\mathrm{C}$, where the sun ray intersects the horizontal plane, two likewise-triangles: $A B C$ and A'B' $C^{\prime}$, will be obtained. By applying the general theorem of the similarity, we obtain:

$$
\frac{C A^{\prime}}{C A}=\frac{C B^{\prime}}{C B}=\frac{A^{\prime} B^{\prime}}{A B}
$$

The distance $d$ will be calculated by the relation (6), for the angle $\alpha_{0}$ corresponding to the optimal case, as described beforehand. The distance $D$ will be determined by the same relation, by changing the angle $\alpha_{0}$ with an angle $\alpha$ for a random calculation hour. The length of the CB' segment will be determined as the difference between $D$ and $d$ :

$$
\begin{aligned}
& C B^{\prime}=D-d=L\left(\cos \beta+\frac{\sin \beta}{\tan \alpha}\right)-L\left(\cos \beta+\frac{\sin \beta}{\tan \alpha_{0}}\right)= \\
& =L\left(\frac{\sin \beta}{\tan \alpha}-\frac{\sin \beta}{\tan \alpha_{0}}\right)=L \sin \beta\left(\frac{\tan \alpha_{0}-\tan \alpha}{\tan \alpha_{0} \tan \alpha}\right)
\end{aligned}
$$

In order to calculate the length $u$ we should keep the second equality from the relation (9) and rewritten their terms according to the notations from the figure 8:

$$
\begin{aligned}
& \frac{D-d}{D}=\frac{u}{L} \\
& u=\frac{L(D-d)}{D}=L \sin \beta \frac{\left(\frac{\tan \alpha_{0}-\tan \alpha}{\tan \alpha_{0} \tan \alpha}\right)}{\left(\cos \beta+\frac{\sin \beta}{\tan \alpha}\right)}
\end{aligned}
$$

By dividing the length $u$ of the shade to the length $L$ of the panel, we obtain a non-dimensional number $U$ named "shading factor":

$$
U=\frac{u}{L}=\sin \beta \frac{\left(\frac{\tan \alpha_{0}-\tan \alpha}{\tan \alpha_{0} \tan \alpha}\right)}{\left(\cos \beta+\frac{\sin \beta}{\tan \alpha}\right)}
$$

This factor represents the percentage of the total panel's surface that is shaded, at a randomly calculation hour. As a result, the total shaded area of the panels, $A_{\text {shaded }}$, will be equal to:

$$
A_{\text {shaded }}=U \cdot A\left[\mathrm{~m}^{2}\right]
$$

where $A\left(\mathrm{~m}^{2}\right)$ represents the cumulated area of the collector's surfaces. In order to obtain the useful energy yield from the solar panels with respect to the shading phenomenon, the total sunlit area, $A_{\text {sunlit }}\left(\mathrm{m}^{2}\right)$ of the panels could be written as:

$$
A_{\text {sunlit }}=A-A_{\text {shaded }}=A(1-U)\left[\mathrm{m}^{2}\right]
$$

In the case of the collectors surfaces placed along a vertical plane (figure 9), the self-shading phenomena are very similar to the horizontal case, with the difference that they appear for solar height angles bigger than the optimal angle $\alpha_{0}$. 
Because the distance $\mathrm{d}$ between the centers of the solar plates is imposed by the manufacturer, the corresponding angle $\alpha_{0}$ will be determined for this distance, by using the same relation (8):

$$
\begin{aligned}
& d=L \sin \beta+L \frac{\cos \beta}{\cot \alpha 0} \\
& d-L \sin \beta=\frac{L \cos \beta}{\cot \alpha o} \\
& \cot \alpha o=\frac{L \cos \beta}{d-L \sin \beta} \\
& \alpha o=\operatorname{arcctg}\left(\frac{L \cos \beta}{d-L \sin \beta}\right)
\end{aligned}
$$

Having in mind that $\alpha_{0}$ and $d$ are already known, the calculation algorithm from the horizontal case with be applied, resulting the length $u$ and by consequent, the shading factor $U$, for vertical surfaces:

$$
\begin{aligned}
& C B^{\prime}=D-d=L\left(\sin \beta+\frac{\cos \beta}{\cot \alpha}\right)-L\left(\sin \beta+\frac{\cos \beta}{\cot \alpha_{0}}\right)= \\
& =L\left(\frac{\cos \beta}{\cot \alpha}-\frac{\cos \beta}{\cot \alpha_{0}}\right)=L \cos \beta\left(\frac{\cot \alpha_{0}-\cot \alpha}{\cot \alpha_{0} \cot \alpha}\right)
\end{aligned}
$$

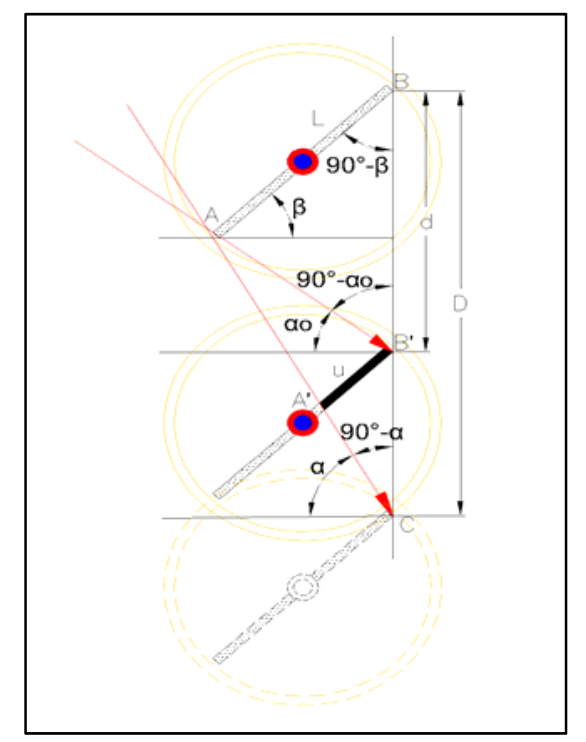

Fig.9 - Self-shading of the solar panels placed on a vertical surface

In order to evaluate the opportunity to place this type of collector on a horizontal or vertical surface, the authors decided to analyze these two case by numerical simulation, applying them for six different Romanian cities: Bucuresti, Constanta, Iasi, Cluj Napoca, Craiova and Timisoara, having different solar radiation charges over the year. The values of the solar beam radiation from these cities were gathered from the Meteonorm software database [20].

\section{Results and discussions}

In the figures 10 and 11 are represented the daily variations of the surfaces exposed to the sun beam radiation, for the six Romanian cities selected and for two significant days of the year: $21^{\text {st }}$ of June corresponding to the summer solstice, and $21^{\text {st }}$ of December, corresponding to the winter solstice. The presented cases correspond to the panel strings placed at a tilt angle of $45^{\circ}$ related to the horizontal surface as well as to the vertical surface. Both panel strings are South-oriented. In the last case, the panel frame was supposed to be vertical, but its absorbent plate had been turned to an angle $\beta$ of $45^{\circ}$ from the horizontal plane, like in figure 9. 
It should be mentioned that, fot the first case, the solar height angle $\alpha_{0}$ calculated at 12:00 A.M. for the $21^{\text {st }}$ of December was used to determine the optimum distance $d$ between two adjacent panels placed one behind the other on a horizontal surface, tilted with $45^{\circ}$ relative to the horizontal plane (see figure 8).

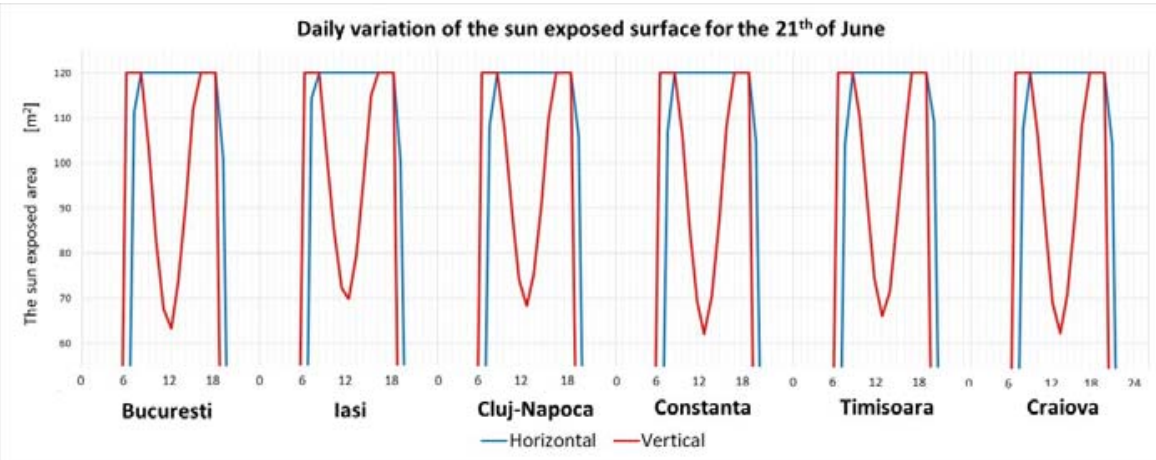

Fig.10 - Daily variation of the sun-exposed surface to beam radiation on the $21^{\text {st }}$ of June

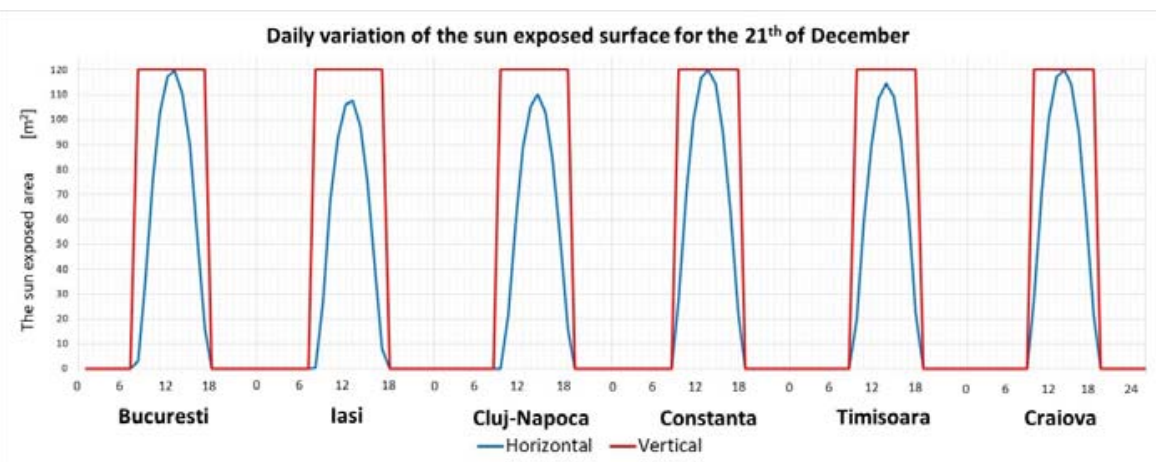

Fig.11 - Daily variation of the sun-exposed surface to beam radiation on the $21^{\text {st }}$ of December

From this figures, the following observations could be made:

- For the summer solstice (figure 10), the daily self-shading phenomenon is significant for the vertical case (the blue curve), with a peak at 12:00 A.M., when the Sun reaches its highest position in the sky; this is due to the important solar height angles characterising the summer period, that lead to a reduced view-factor with the vertical surfaces in opposition with the horizontal ones; as a result, the red curve from the figure 10 shows that on the horizontal surface no shadows appear during this whole summer solstice day, featuring an ideal case of sun radiation caption;

- For the winter solstice (figure 11), the situation appears to be inversed relatively to the previous case: the self-shading phenomenon will be important, at the same peak hour (12:00 A.M.) for the horizontal case, due to the reduced solar height angles, while the vertical surfaces will be practically no shaded at all;

- The behaviour will be similar for the six cities investigated, the differences appearing from the self-shading percentage, depending on the latitude angle.

In the figures 12 to 17 are represented the annual usage degrees (AUD) of the solar beam radiation for the six cities investigated and for the horizontal and vertical position of the solar panels, in order to assess the influence of the local climate of the self-shading magnitude. This non-dimensional factor, AUD (in \%) is defined as the ratio between the sunlit area of the panels, Asunlit $\left(\mathrm{m}^{2}\right)$, defined by equation (14), and the total area of the panels, $\mathrm{A}\left(\mathrm{m}^{2}\right)$ :

$$
A U D=\frac{A_{\text {sunlit }}}{A} 100
$$




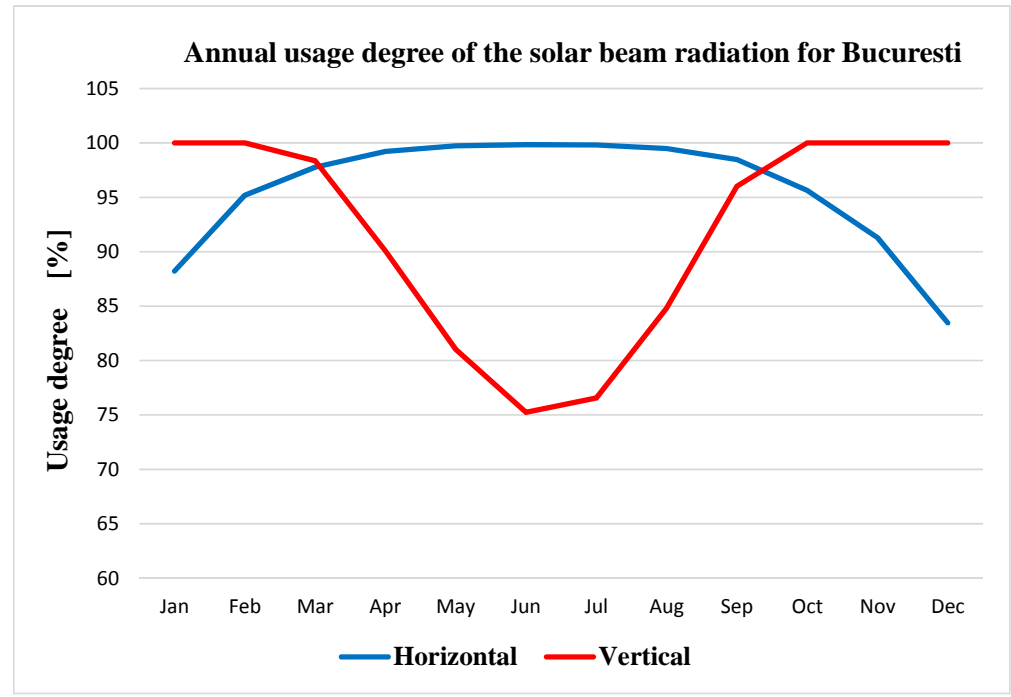

Fig.12 - Annual usage degree for Bucuresti

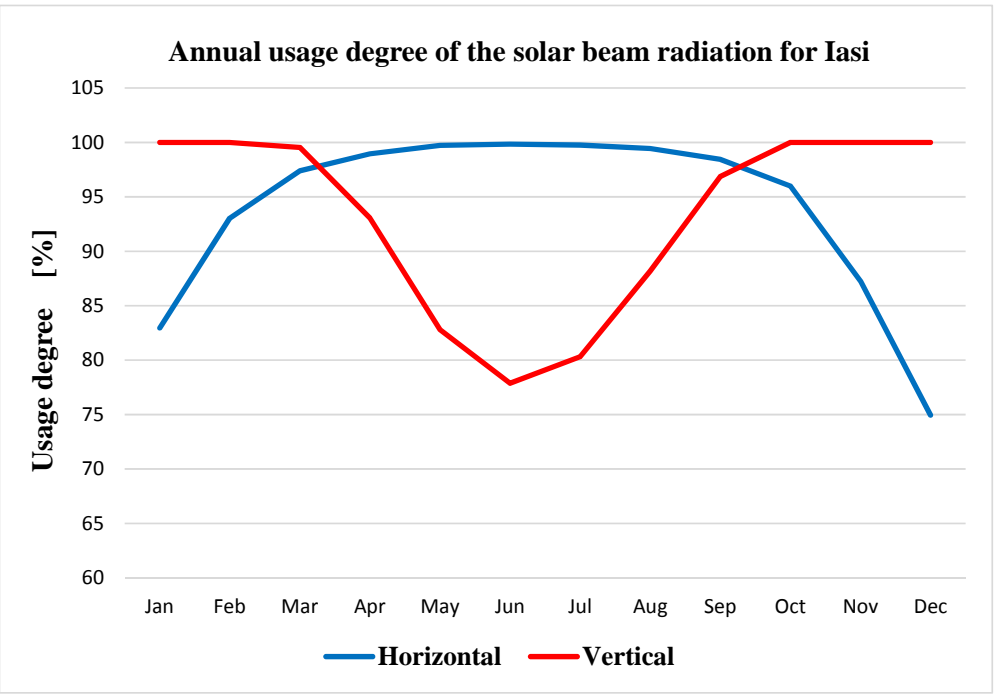

Fig.13 - Annual usage degree for Iasi

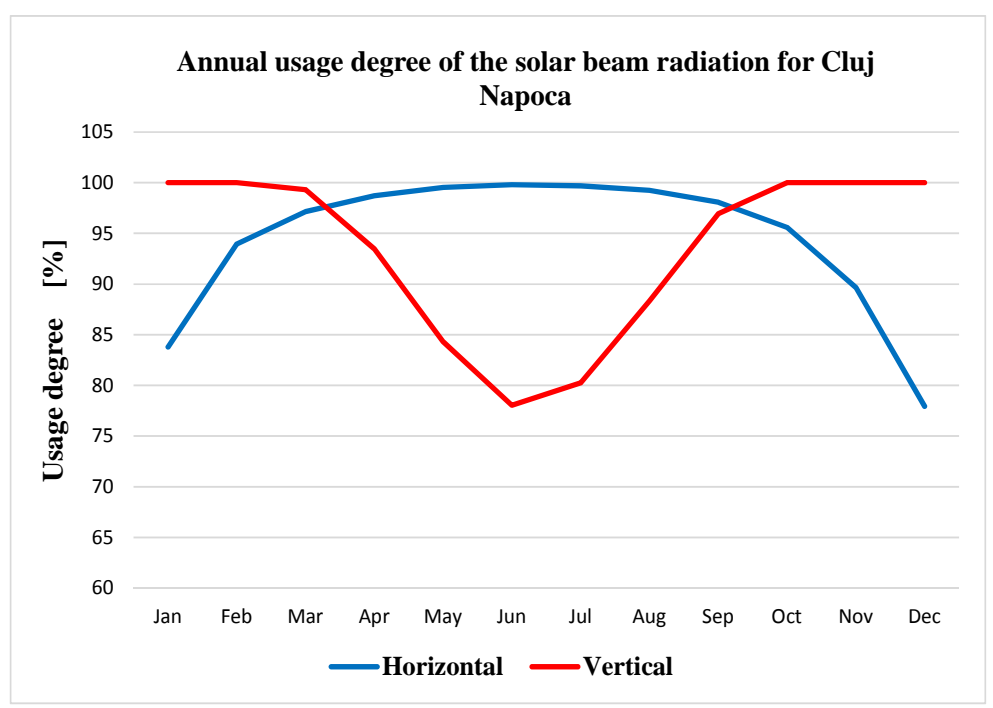

Fig.14 - Annual usage degree for Cluj-Napoca 


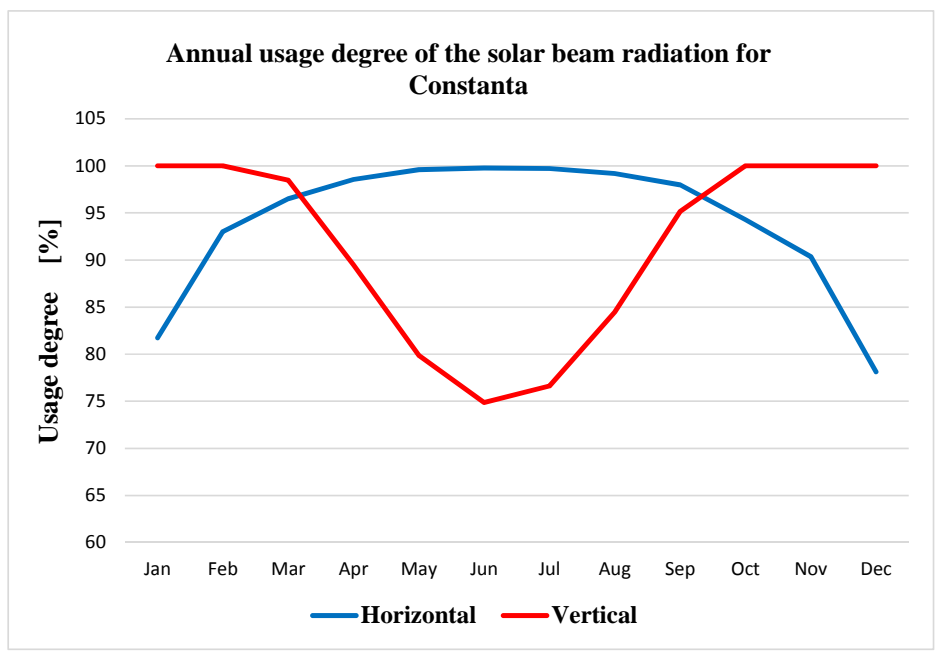

Fig.15 - Annual usage degree for Constanta

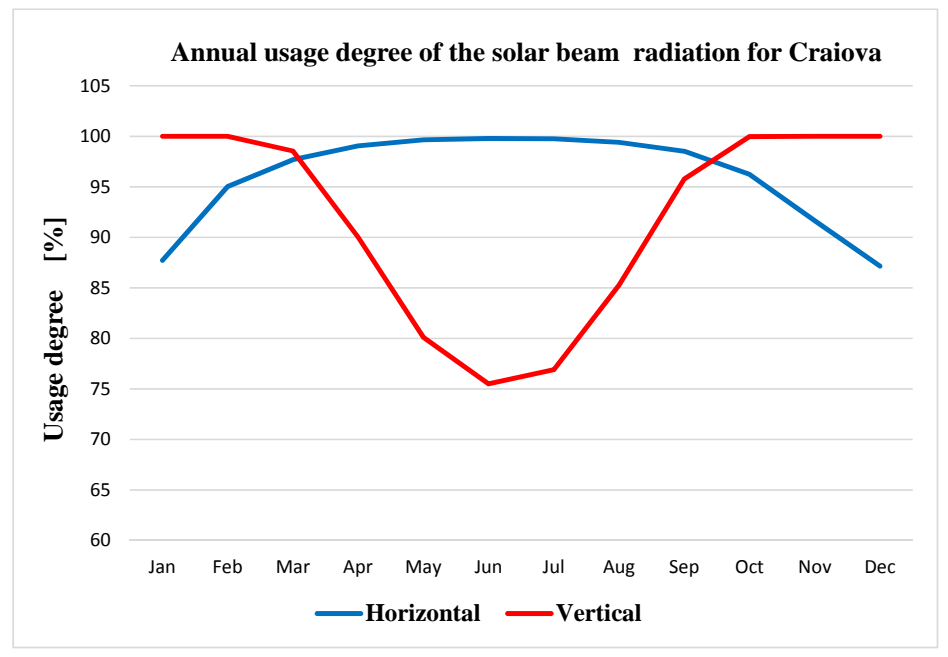

Fig.16 - Annual usage degree for Craiova

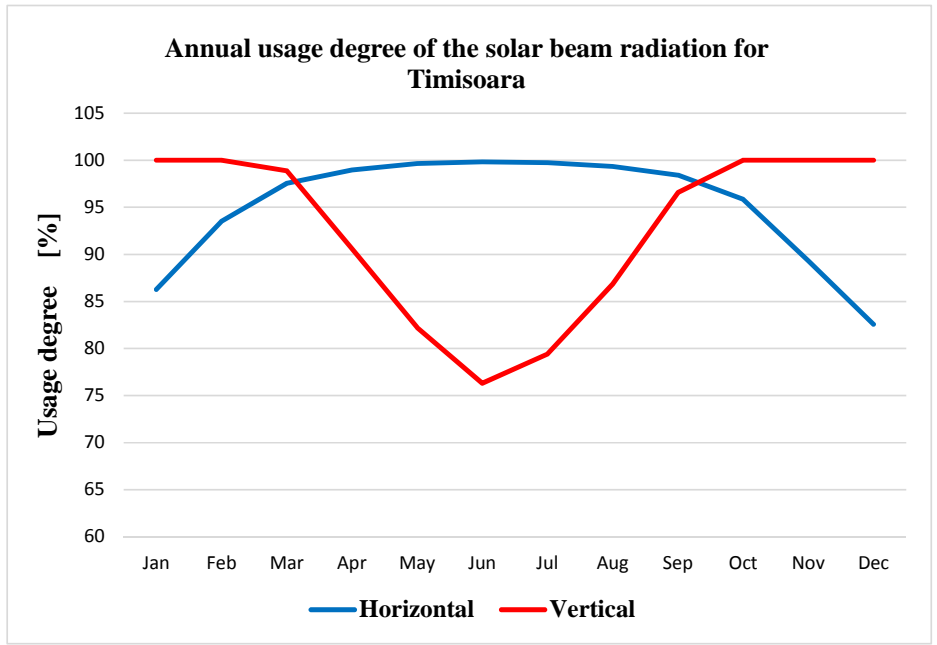

Fig.17 - Annual usage degree for Timisoara

In order to obtain the mean annual usage degree of the solar beam radiation for the six cities, the results, in terms of useful solar beam energy captured by the panels, were integrated over a one year-period, obtaining the values outlined in table 1 hereafter. In table 1 " $\mathrm{H}$ " corresponds to the 
panels installed on the hotizontal surface, while "V" corresponds to the vertical surface mounting.

Table 1

Annual usage degree for the cases investigated

\begin{tabular}{|c|c|c|c|c|c|c|}
\hline & \multirow{3}{*}{$\begin{array}{l}\text { Latitude } \\
\text { angle }\end{array}$} & \multirow{2}{*}{$\begin{array}{c}\text { Theoretical } \\
\text { available } \\
\text { energy }\end{array}$} & \multicolumn{2}{|c|}{$\begin{array}{l}\text { Real available energy } \\
\text { (with self-shading) }\end{array}$} & \multicolumn{2}{|c|}{ Annual usage degree } \\
\hline & & & $\mathrm{H}$ & $\mathrm{V}$ & $\mathrm{H}$ & $\mathrm{V}$ \\
\hline & & [MWh] & [MWh] & [MWh] & {$[\%]$} & {$[\%]$} \\
\hline Bucuresti & $44^{\prime} 30^{\prime \prime} \mathrm{N}$ & 110.3 & 107.3 & 98.5 & 97.3 & 89.3 \\
\hline Iasi & $47^{\prime} 10^{\prime \prime} \mathrm{N}$ & 114.0 & 109.9 & 103.5 & 96.4 & 90.7 \\
\hline Cluj Napoca & $46^{\prime} 47^{\prime \prime} \mathrm{N}$ & 97.4 & 93.9 & 89.0 & 96.5 & 91.4 \\
\hline Constanta & $44^{\prime} 13^{\prime \prime} \mathrm{N}$ & 116.7 & 112.1 & 103.5 & 96.1 & 88.8 \\
\hline Timisoara & $45^{\prime} 46^{\prime \prime} \mathrm{N}$ & 93.7 & 91.2 & 84.2 & 97.3 & 89.8 \\
\hline Craiova & $44^{\prime} 14^{\prime \prime} \mathrm{N}$ & 109.4 & 106.4 & 98.0 & 97.3 & 89.6 \\
\hline
\end{tabular}

The conclusion that could be outlined from the table 1 is that the annual AUD values obtained for the six cities are approaching the $97 \%$ for the horizontal case and $90 \%$ for the vertical case. That means the horizontal position to install the solar panels is much recommended than the vertical mounting along a façade, even for the South orientation. However, the percentage of self-shading over the whole year approaches $10 \%$ from the total vertical surface exposed to the Sun.

These observations are true for the particular case studied in this paper: one individual string of solar panels placed one behind the other. The percentage of self-shading would obviously be greater for parallel strings of solar panels due to the lateral shade produced at the hours approaching sunrise and sunset.

Taking into account that the most important solar beam radiation occurs during the summer period (figure 18), we have decided to make a similar analysis with that presented in table 1, by integrating the solar energy only for the months corresponding to the peak summer period, from May to August. The same type results, but only for the summer season, are presented in table 2 hereafter.

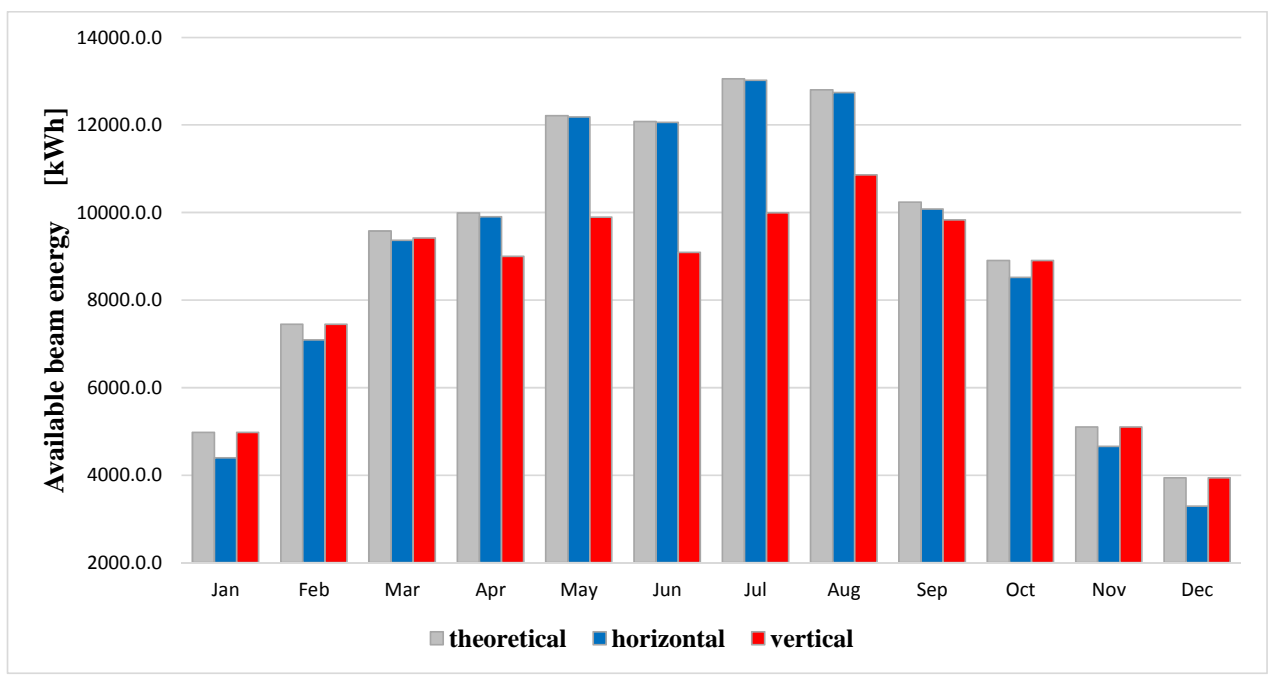

Fig.18 - The annual available beam solar energy for Bucuresti (self-shading) 
Seasonal usage degree for the cases investigated

\begin{tabular}{|c|c|c|c|c|c|c|c|c|}
\hline & \multirow{3}{*}{$\begin{array}{l}\text { Latitude } \\
\text { angle }\end{array}$} & \multirow{2}{*}{$\begin{array}{c}\text { Theoretical } \\
\text { available } \\
\text { energy }\end{array}$} & \multicolumn{2}{|c|}{ Real available energy } & \multicolumn{2}{|c|}{$\begin{array}{l}\text { Seasonal usage } \\
\text { degree }\end{array}$} & \multicolumn{2}{|c|}{$\begin{array}{l}\text { Minimum usage } \\
\text { degree (December } \\
\text { for H, June for } V \text { ) }\end{array}$} \\
\hline & & & $\mathrm{H}$ & $\mathrm{V}$ & $\mathrm{H}$ & $\mathrm{V}$ & $\mathrm{H}$ & $\mathrm{V}$ \\
\hline & & [MWh] & [MWh] & [MWh] & {$[\%]$} & {$[\%]$} & {$[\%]$} & {$[\%]$} \\
\hline Bucuresti & $44^{\prime} 30^{\prime \prime} \mathrm{N}$ & 50153 & 50004 & 39840 & 99.7 & 79.4 & 83 & 75 \\
\hline Iasi & $47^{\prime} 10^{\prime \prime} \mathrm{N}$ & 53351 & 53181 & 43954 & 99.7 & 82.4 & 75 & 78 \\
\hline Cluj Napoca & $46^{\prime} 47^{\prime \prime} \mathrm{N}$ & 43345 & 43151 & 35980 & 99.6 & 83.0 & 78 & 78 \\
\hline Constanta & $44^{\prime} 13^{\prime \prime} \mathrm{N}$ & 53950 & 53716 & 42612 & 99.6 & 79.0 & 75 & 78 \\
\hline Timisoara & $45^{\prime} 46^{\prime \prime} \mathrm{N}$ & 44013 & 43852 & 35798 & 99.6 & 81.3 & 76 & 83 \\
\hline Craiova & $44^{\prime} 14 " \mathrm{~N}$ & 47812 & 47641 & 38036 & 99.6 & 79.6 & 76 & 87 \\
\hline
\end{tabular}

It could be observed from the table 2 that the largest theoretical available solar beam energy occurs for the city of Constanta ( $53950 \mathrm{kWh}$-in bolded black), the best placed on the Romanian solar radiation Map, while the lowest energy is observed for Cluj-Napoca ( $43345 \mathrm{kWh}$ in bolded red). For the horizontal $(\mathrm{H})$ position of the panels, the largest and the lowest real available solar energies appear to occur for the same previous cities: Constanta and Cluj Napoca. The situation becomes different for the vertical (V) position of the panels. Thus, the largest available solar beam radiation for the summer period appears for the city of Iasi, situated at the highest latitude from the six cities, while the lowest available energy is observed for Timisoara.

As it could be seen in table 2 , in terms of seasonal usage degree, the figures obtained for the $\mathrm{H}$ position approach $100 \%$, showing that during the summer months there will be practically no selfshading if the distance $\mathrm{d}$ between two adjacent panels is correctly determined. This observation confirms the same pattern represented in the figure 10, for the summer solstice day (21st June).

For the $\mathrm{V}$ position of the panels, the seasonal usage degree lies around $80 \%$, so $20 \%$ of selfshading is present, reducing the solar beam energy captured by the panels' absorber.

It should be also noted that the minimum usage degree for all the cities occurs in December for the $\mathrm{H}$ position and in June for the $\mathrm{V}$ position, depending on the solar elevation, that is high during the summer period and low during the winter period.

\section{Conclusions}

The paper presents a study focusing on the self-shading phenomenon that could appear for individual strings of solar panels placed on horizontal or vertical surfaces from a building. By using the geometry of the solar angles with respect to building surfaces, the authors have analyzed the magnitude of the panels' shaded areas that occurs during one conventional climatic year, for six Romanian cities for which climatic data had been available. The results showed important differences between horizontal and vertical mountings, especially for the summer period, when the solar beam radiation is higher and essential for the production of thermal energy for DHW purposes. The study opens a good perspective to investigate the self-shading phenomena for more geographical locations, characterized by different solar radiation data.

\section{Acknowledgement}

The work presented in this paper was conducted by a consortium of three universities (Romania, Bulgaria and France), under the framework of international research project (ISERBATURB) financed by the Romanian Agency of Atomic Physics and the French University Agency (AUF). 


\section{References}

[1]. 31/2010/EU Directive (EPBD Recast) of the European Parliament and European Council, on the Buildings Energy Performance, EU Official Journal, 18.06.2010. pp. L153/13 - L153/35.

[2]. European Commission. (2015). Towards an Integrated Strategic Energy Technology (SET) Plan: Accelerating the European Energy System Transformation, Brussels, C(2015) 6317 final report. 17 pages.

[3]. European Technology Platform on Renewable Heating and Cooling. (2015). Solar Heating and Cooling Technology Roadmap, available at http://www.rhc-platform.org/publications/.

[4]. Deutsche Solarthermie-Technologie Plattform. (2014). Forschungsstrategie Niedertemperatur-Solarthermie 2030, available at $h$ ttp://www.solarthermietechnologie.de/home/dsttp-aktuelles/detailansicht/browse/2/article/35/solarwaerme-f/.

[5]. Cappel C, Tilmann E.K., Maurer C. (2014). Research and Development Roadmap for façade-integrated solar thermal systems. Fraunhofer-Institut fur Solare Energiesysteme. ISE. 50 pages.

[6]. Kalogirou S.A. et al. (2017). Building Integration of Solar Thermal Systems. Design and Applications Handbook, COST Action TU1205. 455 pages.

[7]. Munari Probst M.C., Roecker C. (2007). Towards an improved architectural quality of building integrated solar thermal systems (BIST).Solar Energy 81. pp.1104-1116.

[8]. Lamnatou C., Mondol J.D., Chemisana D., Maurer C. (2015). Modelling and simulation of Building-Integrated solar thermal systems :Behaviour of the coupled building/system configuration, Renewable and Sustainable Energy Reviews 48. pp.178-191.

[9]. Lamnatou C., Mondol J.D., Chemisana D., Maurer C. (2015). Modelling and simulation of Building-Integrated solar thermal systems :Behaviour of the system configuration. Renewable and Sustainable Energy Reviews 45. pp.36-51.

[10]. Delisle V., Kummert M. (2016). Cost-benefit analysis of integrating BIPV-T air systems into energyefficient homes. Solar Energy 136. pp.385-400.

[11]. Shukla A.K., Sudhakar K., Baredar P. - Recent advancement in BIPV product technologies: A review, Energy and Buildings 140 (2017). pp.188-195.

[12]. Visa I., Moldovan M., Comsit M., Neagoe M., Duta A. (2017). Facades integrated solar-thermal collectors- challenges and solutions. Energy Procedia 112. pp.176-185.

[13]. Dupeyrat P., Menezo C., Fortuin S. (2014). Study of th thermal and electrical performances of PVT solar hot water systems. Energy and Buildings 68. pp. 751-755.

[14]. Fudholi A., Sopian K., Yazdi M.H., Ruslan M.H., Ibrahim A., Kazem H.A. (2014). Performance analysis of photovoltaic thermal (PVT) water collectors. Energy Conversion and Management 78. pp.641-651.

[15]. Rommel M., Zenhausern D., Baggenstos A., Turk O., Brunold S. (2015). Development of glazed and unglazed PVT collectors and first results of their application in different projects. Energy Procedia 70. pp.318-323.

[16]. Aste N., Del Pero C., Leonforte F. (2012). Optimization of solar thermal fraction in PVT systems. Energy Procedia 30. pp.8-18.

[17]. Meteonorm software - available at www.meteonorm.com. 